\title{
EFEITO DO TRATAMENTO TÉRMICO EM SEMENTES DE ABÓBORAS (Cucurbita spp.) SOBRE OS NÍVEIS DE FATORES ANTINUTRICIONAIS E/OU TÓXICOS ${ }^{1}$
}

\author{
Effect of the thermal processing on pumpkin seeds (Cucurbita spp.) \\ on the levels of antinutritionales factors and/or toxics
}

\author{
Glauciemar Del-Vechio², Angelita Duarte Corrêa ${ }^{3}$, Celeste Maria Patto de Abreu ${ }^{3}$, \\ Custódio Donizete dos Santos ${ }^{3}$
}

\begin{abstract}
RESUMO
Os teores de alguns antinutrientes de sementes cruas, cozidas e tostadas de três espécies de abóboras, Cucurbita maxima (CMA), C. moschata (CMO) e o híbrido F1 (CMA X CMO), foram investigados, a fim de assegurar o seu uso em preparações dietéticas, produtos industrializados e formulações de novos produtos. Não foram detectados em nenhuma das espécies estudadas teores de ácido oxálico e nitrato. A espécie C. maxima apresentou os níveis mais baixos de cianeto e de polifenóis e maior digestibilidade protéica in vitro. O cozimento acarretou redução nos níveis de cianeto, inibidor de tripsina, da atividade de hemaglutinina e de polifenóis e aumento da digestibilidade protéica in vitro. Dos tratamentos térmicos utilizados, o cozimento foi o mais eficiente na redução desses constituintes.
\end{abstract}

Termos para indexação: Sementes de abóbora, tratamento térmico, antinutrientes, digestibilidade protéica.

\begin{abstract}
The contents of some antinutrients of raw, boiled and toasted seeds of three pumpkin species, Cucurbita maxima (CMA), C. moschata (CMO) and the F1 hybrid (CMA x CMO), were investigated in order to assure the use in dietary preparations industrialized products and formulations of new products. Levels of oxalic acid and nitrate were not detected in any of the species studied. CMA presented the lowest levels of cyanide, polyphenols and highest in vitro protein digestibility. Cooking brought about reduction in the levels of cyanide, trypsin inhibitor, hemaglutinin activity and polyphenols and increased of in vitro protein digestibility. Of the thermal processing employed, cooking was the most efficient in reducing of that constituints.
\end{abstract}

Index terms: Pumpkin seeds, thermal processing, antinutrients, protein digestibility.

(Recebido para publicação em 27 de abril de 2004 e aprovado em 19 de Janeiro de 2005)

\section{INTRODUÇÃO}

O aumento do consumo, gerado pelo crescimento da população mundial, ocasionou a escassez de alguns alimentos, aumentando assim a subnutrição protéica em regiões economicamente pouco desenvolvidas. $\mathrm{O}$ desenvolvimento tecnológico e científico permitiu avaliar o valor nutritivo de diversos alimentos não convencionais. Isso fez com que sementes de várias espécies vegetais se tornassem recursos alternativos de proteínas para a alimentação humana. Desse modo, o que antes era considerado mérito somente da soja ampliou-se para outras sementes, como, por exemplo, a de abóboras (CERLETTI et al., 1978; MONTEIRO, 1992). As sementes de abóbora são muito utilizadas em países da África e fazem parte da chamada "multimistura” no Brasil, ou seja, um alimento preparado por "misturas" de diversas fontes de minerais, carboidratos, proteínas e vitaminas e é formado principalmente por subprodutos dos alimentos consumidos pela população (BRANDÃO \& BRANDÃO, 1996).

$\mathrm{O}$ uso de concentrados de minerais e vitaminas (farelos, pó de folhas, pó de sementes) em doses mínimas, mas constantemente acrescidos à alimentação tradicional, fornece nutrientes que são indispensáveis para promover o crescimento, aumentar a resistência à infecções e manter a saúde. Estudos relatam diversos nutrientes encontrados nas sementes de abóboras, como minerais, proteínas, lipídeos e fibras.

Sabe-se que o conhecimento dos nutrientes nos alimentos não é suficiente para avaliar sua qualidade nutricional, pois nem todos são totalmente disponíveis ao organismo após ingestão. Fatores antinutricionais podem interferir na biodisponibilidade dos nutrientes ou ser tóxicos, surgindo assim preocupação na escolha do alimento, bem como das partes que serão consumidas e quais os processamentos mais adequados (LIENER, 1980).

1. Parte da dissertação de Mestrado do primeiro autor apresentado à Universidade Federal de Lavras/UFLA

2. Mestre em Agronomia - Agroquímica/Agrobioquímica - Rua João Mourão, 14 - Centro - São João Del Rei - glauciemar@yahoo.com.br

3. Professores do Departamento de Química /UFLA - Caixa Postal 3037 - 37200-000 - Lavras, MG. 
Entre esses fatores antinutricionais foram estudados o oxalato, nitrato, cianeto, inibidor de tripsina, hemaglutinina e polifenóis. A presença de cianógenos nos alimentos pode causar hipertireoidismo (resultante da interferência do tiocianato no metabolismo do iodo), neuropatia atóxica tropical, paralisia rápida e permanente (OSUNTOKUN, 1981) e até a morte por asfixia.

O efeito tóxico do ácido oxálico no organismo deve-se à formação de cristais de oxalato de cálcio e sua precipitação no organismo, diminuindo a disponibilidade para realização de numerosos processos fisiológicos (FABRE \& TRUHAUT, 1971; MASSEY et al., 1993).

Os nitratos estão presentes em todas as plantas e são fontes essenciais de nitrogênio para o crescimento normal (WALKER, 1975). Há evidências de que os nitratos podem interferir no metabolismo da vitamina A e nas funções da glândula tireóide (SWAN, 1975). Além disso, a alta ingestão de nitratos e sua redução a nitritos podem desencadear reações que os convertem em substâncias tóxicas.

Os inibidores de tripsina, particularmente da soja, são os mais estudados e os mais conhecidos. Eles são os responsáveis pela diminuição da digestibilidade protéica de leguminosas que foram insuficientemente cozidas. Estão relacionados com a redução da taxa de crescimento e alterações metabólicas do pâncreas em monogástricos (SGARBIERI, 1987). Os inibidores de proteases, em sua maioria, são destruídos pelo calor, melhorando o valor nutritivo da proteína.

As hemaglutininas interagem com a mucosa intestinal, causando inflamação e interferindo na absorção de nutrientes por lesão da mucosa. No fígado ocorrem degeneração gorda e necrose. Provoca ainda hipersensibilidade do sistema imune local ou sistêmico e lesão direta do tecido. Elas são estáveis contra a ação de um grande número de enzimas proteolíticas e, de modo geral, são lábeis ao calor, sendo sua ação específica destruída pelo cozimento (LIENER, 1986).

Compostos fenólicos de plantas, tais como antocianinas, antoxantinas, bioflavonóides, catequinas e taninos inibem a atividade de enzimas digestivas como a $\alpha$-amilase, trypsina, quimotripsina e lipase (SALUNKHE et al., 1982). A presença de taninos tem se tornado nutricionalmente indesejável, pelo fato de promover a baixa biodisponibilidade de macromoléculas, como proteínas e carboidratos, aminoácidos, vitaminas e minerais, pela formação de complexos (CHUNG et al., 1998).

As substâncias antinutritivas e/ou tóxicas presentes nas sementes de abóbora são pouco estudadas, tornando-se necessária uma avaliação desses constituintes.
Portanto, no presente trabalho determinou-se os teores de alguns fatores antinutricionias e/ou tóxicos em sementes de três espécies de abóboras, avaliando o efeito do tratamento térmico, a fim de lhes assegurar o uso em preparações dietéticas, produtos industrializados e formulações de novos produtos.

\section{MATERIAL E MÉTODOS}

\section{Preparo das amostras}

As abóboras de duas espécies, Cucurbita maxima (CMA) e Cucurbita moschata (CMO) e o híbrido F1 (CMA x CMO), foram obtidas do comércio varejista de hortifrutigranjeiros de Lavras, MG. Elas foram lavadas e sanitizadas em hipoclorito de sódio (200 $\mathrm{mg} / \mathrm{kg}$ ), por imersão, por 10 minutos. A seguir, foram cortadas; as sementes separadas receberam os seguintes tratamentos: a) usadas na forma natural (sementes cruas), b) cozidas em água de ebulição por 10 minutos, numa proporção de $1 \mathrm{~g}$ de sementes : $10 \mathrm{~mL}$ de água (sementes cozidas), c) tostadas em estufa a $100^{\circ} \mathrm{C}$ por 90 minutos (sementes tostadas).

As sementes cruas e cozidas foram liofilizadas até peso constante. Após a liofilização, todas as sementes foram trituradas em moinho com peneira de 40 mesh e armazenadas em frascos de vidro hermeticamente fechados à temperatura ambiente até a realização das análises.

\section{Análises químicas}

\section{Oxalato}

O ácido oxálico foi extraído a quente com ácido clorídrico, precipitado e quantificado pela titulação do oxalato de cálcio com permanganato de potássio (LOURES \& JOKL, 1990).

\section{Nitrato}

O nitrato foi extraído com água deionizada a $45^{\circ} \mathrm{C}$. Na dosagem, um complexo é formado pela nitração do ácido salicílico sob condições altamente ácidas, procedendo-se à leitura a $410 \mathrm{~nm}$ em soluções básicas (pH maior que 12). A absorbância do material foi diretamente proporcional à quantidade de nitrato presente, sem a ocorrência da interferência de íons amônio, nitrito ou cloro. O nitrato de potássio foi empregado como padrão (CATALDO et al., 1975).

\section{Cianeto}

A extração dos glicosídeos cianogênicos da farinha de sementes de abóbora (FSA) foi feita utilizandose solução de ácido clorídrico e a concentração de 
cianeto medida após a ação enzimática da $\beta$-glicosidase, conforme metodologia descrita por Corrêa et al. (2002).

\section{Inibidor de tripsina}

O inibidor de tripsina da FSA foi extraído com solução de $\mathrm{NaOH}$ 0,01 mol/L em agitação magnética, por 1 hora, à temperatura ambiente. Após centrifugação, uma alíquota do sobrenadante foi usada no ensaio enzimático, empregando-se o BApNA (benzoil-DLarginina-p-nitroanilida) como substrato e a enzima, tripsina. Se existir inibidor na amostra, este inibe a ação da tripsina sobre o BApNA. A leitura da mistura foi feita a $410 \mathrm{~nm}$. A atividade do inibidor de tripsina foi expressa em termos de unidade de tripsina inibida (UTI)/mg matéria seca (KAKADE et al., 1969, 1974).

\section{Hemaglutinina}

Realizou-se a extração de hemaglutinina com 0,25 g da FSA em $5 \mathrm{~mL}$ de $\mathrm{NaCl}$ 0,85 g/100 mL $(\mathrm{pH}=7,4)$, agitando-se por três horas, à temperatura ambiente e filtrando-se o extrato. A estimativa da atividade aglutinante foi aplicada pela placa de microtitulação, adicionando-se $100 \mu \mathrm{L}$ de suspensão de eritrócitos 2\% (sangue humano $\mathrm{B}^{+}$) e $100 \mu \mathrm{L}$ do extrato da amostra, fazendo-se uma série de diluições na base $2\left(2^{0}, 2^{1}, 2^{2}, 2^{3}\right.$, etc.), deixando-se em repouso por 1 hora, à temperatura ambiente. Posteriormente, verificou-se, por meio da leitura visual, a presença ou não de aglutinação de células sangüíneas, sendo o resultado confirmado após 30 minutos. Paralelamente, utilizou-se uma testemunha, que consistiu apenas de suspensão de eritrócitos. Os resultados foram expressos pelo expoente de base 2, correspondente à última diluição em que foi observada aglutinação visível de eritrócitos (FIGUEROA \& LAJOLO, 1997).

\section{Polifenóis}

Os polifenóis da FSA foram extraídos com metanol a 50\%, em refluxo, por três vezes consecutivas. Os extratos foram reunidos, evaporados até o volume de $10 \mathrm{~mL}$ e submetidos à dosagem de polifenóis, segundo Folin-Denis, usando ácido tânico como padrão (GOLDSTEIN \& SWAIN, 1963).

\section{Digestibilidade protéica in vitro}

A FSA, com teor de nitrogênio conhecido, foi submetida à digestão com as enzimas pepsina e pancreatina, em seus $\mathrm{pH}$ ótimos e a digestão foi interrompida com a adição de ácido tricloroacético. Fez-se a centrifugação, dosando-se o nitrogênio no sobrenadante
(AKESON \& STAHMANN, 1964). A caseína foi usada como padrão e também serviu de controle. A digestibilidade da caseína foi corrigida para $100 \%$ e a da farinha foi corrigida em relação à da caseína, sendo os resultados expressos em porcentagem.

\section{Análises estatísticas}

O experimento foi realizado em delineamento estatístico inteiramente casualizado, em esquema fatorial $3 \times 3$, ou seja, três cultivares, três tratamentos térmicos das sementes, com três repetições de dois frutos, para C. maxima e C. moschata e três frutos para o híbrido F1. Os dados foram submetidos à análise de variância, utilizando o teste de F. O teste de Tukey foi usado para as comparações de médias de espécies e tratamentos, a 5\% de probabilidade (PIMENTELGOMES, 1990). As análises estatísticas foram realizadas segundo técnicas usuais do software Sisvar (FERREIRA, 2000).

\section{RESULTADOS E DISCUSSÃO}

Ácido oxálico e nitrato não foram detectados em nenhuma das espécies estudadas.

$\mathrm{Na}$ análise de variância de cianeto, inibidor de tripsina e polifenóis, verifica-se que houve diferenças significativas entre as espécies ( $\mathrm{E})$, tratamento térmico (T) e na interação E x T. Porém, o mesmo não aconteceu na interação $\mathrm{E}$ x $\mathrm{T}$ para a digestibilidade protéica in vitro (Tabela 1 ).

Na Tabela 2 verificam-se os teores médios de cianeto das três espécies de abóbora estudadas, nos três tratamentos. A espécie $C$. maxima apresentou os níveis mais baixos de cianeto, exceto para as sementes cozidas, porém, não foi estatisticamente diferente da $C$. moschata cozida. Os tratamentos a quente levaram à redução dos níveis de cianeto, sobretudo o cozimento. O cozimento causou maior redução nos níveis de cianeto comparado à tostagem, provavelmente, porque a enzima que degrada o substrato glicosídeo cianogênico é hidrolítica e, portanto, necessita da presença de água para atuar. Assim, à medida que a semente foi sendo tostada, ela foi também perdendo água e diminuindo a ação da enzima. Além disso, a temperatura e o tempo de tostagem, maiores que o do cozimento, podem ter causado desnaturação da enzima.

A dose letal de cianeto oscila entre 0,5 a 3,5 $\mathrm{mg} / \mathrm{kg}$ de peso corpóreo (WOGAN \& MARLETTA, 1993). Para um indivíduo de $70 \mathrm{~kg}$, seria considerado 
TABELA 1 - Análise de variância de antinutrientes das FSA de três espécies submetidas a diferentes processamentos.

\begin{tabular}{lccccc}
\hline & & \multicolumn{4}{c}{ Quadrado médio } \\
\cline { 3 - 5 } Fontes de variação & GL & Cianeto & $\begin{array}{c}\text { Inibidor de } \\
\text { tripsina }\end{array}$ & Polifenóis & $\begin{array}{c}\text { Digestibilidade } \\
\text { protéica in vitro }\end{array}$ \\
\hline Espécie (E) & 2 & $16,832^{* *}$ & $22,662^{* *}$ & $7,333^{* *}$ & $1309,268^{* *}$ \\
Tratamento térmico(T) & 2 & $49,695^{* *}$ & $24,262^{* *}$ & $3,564^{* *}$ & $543,591^{* *}$ \\
E x T & 4 & $7,330^{* *}$ & $3,984^{* *}$ & $0,904^{* *}$ & $7,703 \mathrm{NS}$ \\
Erro & 18 & 0,209 & 0,081 & 0,099 & 4,967 \\
\hline Coeficiente de variação & & $6,79 \%$ & $13,33 \%$ & $10,79 \%$ & $3,75 \%$ \\
\hline
\end{tabular}

FSA = farinha de sementes de abóbora; GL = grau de liberdade; NS = não-significativo.

** Teste F significativo a $1 \%$ de probabilidade.

TABELA 2 - Teores de cianeto (mg/100 g matéria seca) ${ }^{1}$ das FSA de três espécies submetidas a diferentes tratamentos térmicos.

\begin{tabular}{lccc}
\hline & Cruas & Cozidas & Tostadas \\
\hline C. maxima & $7,00 \mathrm{aB}$ & $4,44 \mathrm{cAB}$ & $5,52 \mathrm{bB}$ \\
C. moschata & $7,64 \mathrm{aB}$ & $3,75 \mathrm{bB}$ & $7,40 \mathrm{aA}$ \\
híbrido F1 & $12,48 \mathrm{aA}$ & $4,84 \mathrm{cA}$ & $7,49 \mathrm{bA}$ \\
\hline
\end{tabular}

${ }^{1}$ Médias seguidas da mesma letra minúscula nas linhas e maiúscula nas colunas não diferem entre si (teste Tukey $\mathrm{p} \leq 0,05)$. FSA $=$ farinha de sementes de abóbora.

seguro o consumo de, no máximo, cerca de $250 \mathrm{~g}$ da FSA (levando em consideração o teor da semente crua do hibrido F1). Essa quantidade pode ser considerada relativamente grande, pois a farinha apresenta baixa densidade. Porém, é necessário ressaltar a toxicidade crônica atribuída ao consumo de doses menores de cianeto em um intervalo de tempo maior (OSUNTOKUN, 1981).

Na Tabela 3 encontram-se os teores médios de inibidores de tripsina. O cozimento acarretou diminuição nos níveis dessa substância, apresentando-se mais eficiente que a tostagem. Condições como as utilizadas no cozimento convencional são geralmente suficientes para inativar de forma significativa ou mesmo completa os inibidores de proteases (BRESSANI, 1993;
GENOVESE \& LAJOLO, 2000; VIDAL-VALVERDE et al., 1994).

Comparando com a soja crua, que contém 37,73 a 51,68 UTI/mg matéria seca (BARCELOS, 1998; HAFEZ, 1983) as FSA apresentaram níveis bastante inferiores $(0,88$ a $6,24 \mathrm{UTI} / \mathrm{mg}$ matéria seca).

A atividade hemaglutinante das FSA cruas de C. moschata e híbrido F1 foram maiores que a da $C$. maxima (Tabela 4). Entretanto, após cozimento, houve uma redução da atividade em todas as espécies. Também houve uma redução, embora menor, nessas duas espécies, após tostagem. As três espécies tiveram atividades de aglutinação consideradas iguais após o cozimento e a tostagem. 
TABELA 3 - Teores de inibidor de tripsina (UTI/mg matéria seca) ${ }^{1}$ das FSA de três espécies submetidas a diferentes tratamentos térmicos.

\begin{tabular}{llll}
\hline & Cruas & Cozidas & Tostadas \\
\hline C. maxima & $6,24 \mathrm{aA}$ & $1,39 \mathrm{cA}$ & $3,38 \mathrm{bA}$ \\
C. moschata & $4,69 \mathrm{aB}$ & $0,58 \mathrm{cB}$ & $1,44 \mathrm{bB}$ \\
híbrido F1 & $0,88 \mathrm{aC}$ & $0,19 \mathrm{bB}$ & $0,43 \mathrm{abC}$ \\
\hline
\end{tabular}

UTI = unidades de tripsina inibida; FSA = farinha de sementes de abóbora.

${ }^{1}$ Médias seguidas da mesma letra minúscula nas linhas e maiúscula nas colunas não diferem entre si (teste Tukey $\mathrm{p} \leq 0,05$ ).

TABELA 4 - Atividade hemaglutinante* das FSA submetidas a diferentes tratamentos térmicos.

\begin{tabular}{ccccccccc}
\hline & C. maxima & & \multicolumn{3}{c}{ C. moschata } & \multicolumn{3}{c}{ Híbrido F1 } \\
\hline Cruas & Cozidas & Tostadas & Cruas & Cozidas & Tostadas & Cruas & Cozidas & Tostadas \\
2 & 1 & 2 & 3 & 1 & 2 & 3 & 1 & 2 \\
\hline
\end{tabular}

${ }^{*} \mathrm{O}$ resultado indica a maior diluição do extrato que ainda produziu aglutinação visível em sangue (tipo $\mathrm{B} \mathrm{RH}^{+}$). $\mathrm{O}$ número expressa o expoente da base 2 , referente à diluição. Os dados são a média de três repetições. FSA = farinha de sementes de abóbora.

Fernández et al. (1982) observaram em extratos de feijão preto, branco e vermelho crus, a produção de aglutinação de soluções de eritrócitos até a diluição $10^{4}$ e $10^{6}$. Portanto, a FSA apresentou valores bem inferiores $\left(2^{2}\right.$ a $\left.2^{3}\right)$. Todavia, a toxicidade da hemaglutinina da FSA deveria ser investigada, uma vez que a toxidez não está apenas relacionada com a atividade hemaglutinante.

A C. maxima apresentou os teores mais baixos de polifenóis, não sendo significativamente diferente da C. moschata (Tabela 5). Observa-se que as sementes tostadas apresentaram níveis mais elevados de polifenóis. Isto pode ser explicado porque um dos constituintes fenólicos presente nas sementes das abóboras estudadas são as cumarinas. A ação de calor sobre o anel lactônico do ácido transcinâmico favorece a transformação da posição trans para cis. Quando ocorre essa transformação, há uma aproximação da hidroxila com o ácido carboxílico que reage e libera água, possibilitando, assim, a ciclização e, conseqüentemente, a formação da cumarina (SIMÕES et al., 2000). Portanto, o aumento dos polifenóis nas sementes das abóboras tostadas deve-se, provavelmente, ao aumento de cumarinas.

Em relação a digestibilidade protéica in vitro, os percentuais mais elevados foram encontrados na espécie C. maxima - 70,29\%, seguidos pela C. moschata - 61,41\% e híbrido F1 - 46,43\% (Tabela 6). Observa-se que entre as espécies a C. maxima contém o maior teor de inibidor de tripsina (Tabela 3) e o menor nível de polifenóis (Tabela 5), apresentando a maior digestibilidade protéica (Tabela 6). Todavia, o híbrido F1 apresentou os níveis mais baixos e elevados de inibidor de tripsina e polifenóis, respectivamente, e a menor digestibilidade. Como os níveis de inibidor de tripsina são relativamente baixos, é provável que eles não sejam suficientes para causar efetivamente redução da digestibilidade protéica. Além dos polifenóis, outras substâncias, como as fibras alimentares, podem reduzir a digestibilidade protéica e talvez os seus níveis sejam diferentes entre as espécies. 
TABELA 5 - Teores de polifenóis (mg/g matéria seca) ${ }^{1}$ das FSA de três espécies submetidas a diferentes tratamentos térmicos.

\begin{tabular}{lccc}
\hline & Cruas & Cozidas & Tostadas \\
\hline C. maxima & $2,25 \mathrm{abB}$ & $1,76 \mathrm{bB}$ & $2,49 \mathrm{aB}$ \\
C. moschata & $2,61 \quad \mathrm{~B}$ & $2,42 \mathrm{AB}$ & $3,03 \quad \mathrm{~B}$ \\
híbrido F1 & $3,42 \mathrm{bA}$ & $3,00 \mathrm{bA}$ & $5,34 \mathrm{aA}$ \\
\hline
\end{tabular}

${ }^{1}$ Médias seguidas da mesma letra minúscula nas linhas e maiúscula nas colunas não diferem entre si (teste Tukey $\mathrm{p} \leq 0,05$ ). FSA = farinha de sementes de abóbora.

TABELA 6 - Digestibilidade protéica in vitro das FSA de três espécies.

\begin{tabular}{lc}
\hline Espécies & $\begin{array}{c}\text { Digestibilidade protéica } \\
\text { in vitro }(\mathbf{\%})^{\mathbf{1}}\end{array}$ \\
\hline C.maxima & $70,29 \mathrm{~A}$ \\
C.moschata & $61,41 \mathrm{~B}$ \\
Híbrido F1 & $46,43 \mathrm{C}$ \\
\hline
\end{tabular}

FSA = farinha de sementes de abóbora .

${ }^{1}$ Médias seguidas da mesma letra maiúscula não diferem entre si (teste Tukey $\mathrm{p} \leq 0,05$ ).

Constata-se que o cozimento aumentou e a tostagem reduziu significativamente a digestibilidade protéica (Tabela 7). Isto pode ser justificado, provavelmente, pela diminuição dos níveis de polifenóis nas sementes cozidas e aumento nas tostadas (Tabela 5), ou ainda porque a tostagem pode ter provocado reações de Maillard impedindo a ação das enzimas digestivas.

TABELA 7 - Digestibilidade protéica in vitro das FSA submetidas a diferentes tratamentos térmicos.

\begin{tabular}{lc}
\hline Tratamento térmico & $\begin{array}{c}\text { Digestibilidade protéica } \\
\text { in vitro (\%) }\end{array}$ \\
\hline Cruas & $59,87 \mathrm{~b}$ \\
Cozidas & $66,89 \mathrm{a}$ \\
Tostadas & $51,87 \mathrm{c}$ \\
\hline
\end{tabular}

FSA = farinha de sementes de abóbora .

${ }^{1}$ Médias seguidas da mesma letra minúscula não diferem entre si (teste Tukey $\mathrm{p} \leq 0,05$ ).

\section{CONCLUSÕES}

Das espécies estudadas, a C. maxima apresentou os níveis mais baixos de cianeto e polifenóis, mais elevado de inibidor de tripsina e a melhor digestibilidade protéica, enquanto o híbrido F1 o mais baixo de inibidor de tripsina.

O cozimento acarretou redução nos níveis de cianeto, de inibidor de tripsina, da atividade de hemaglutinina e de polifenóis. Como conseqüência, houve aumento da digestibilidade protéica. Portanto, dos tratamentos térmicos usados, o cozimento foi o mais eficiente na redução desses constituintes.

\section{AGRADECIMENTOS}

À CAPES, pela bolsa de mestrado concedida e a FAPEMIG, pelo auxílio financeiro.

\section{REFERÊNCIAS BIBLIOGRÁFICAS}

AKESON, W. R.; STAHMANN, M. A. A pepsin pancreatin digest index of protein quality evaluation. Journal of Nutrition, Bethesda, v. 83, p. 257-261, 1964.

BARCELOS, M. de F. P. Ensaio tecnológico, bioquímico e sensorial de soja e guandu enlatados no estágio verde e maturação de colheitas. 1998. 160 f. Tese (Doutorado em Ciência da Nutrição) Universidade de Campinas, Campinas, 1998.

BRANDÃO, C. T.; BRANDÃO, R. F. Alimentação alternativa. Brasília: CNBB-Pastoral da Criança, 1996. 95 p.

BRESSANI, R. Grain quality of common beans. Food Review International, [S.l.], v. 9, n. 2, p. 237-297, 1993. 
CATALDO, D. A.; HAROON, M.; SCHRADER, L. E.; YOUNG, V. L. Rapid colorimetric determination of nitrate in plant tissue by nitration of salicylic acid. Communications in Soil Science and Plant Analysis, New York, v. 6, n. 1, p. 71-80, 1975.

CERLETTI, P.; FUMAGALLI, A.; VENTURINI, D. Protein composition of seed of Pupinus albus. Journal of Food Science, Chicago, v. 43, p. 1409-1414, 1978.

CHUNG, K. T.; WONG, T. Y.; WEI, C. I.; HUANG, Y. W.; LIN, Y. Tannins and human health: a review. Critical Review in Food Science and Nutrition, Boca Raton, v. 38, n. 6, p. 421-464, June 1998.

CORRÊA, A. D.; SANTOS, C. D.; NATIVIDADE, M. A. E.; ABREU, C. M. P.; XISTO, A. L. R. P.; CARVALHO, V. D. Farinha de folhas de mandioca: I. efeito da secagem das folhas sobre a atividade da linamarase. Ciência e Agrotecnologia, Lavras, v. 26, n. 2, p. 368-374, mar./abr. 2002.

FABRE, R.; TRUHAUT, R. Toxicologia. Lisboa: Fundação Calouste Gulbenkian, 1971. 887 p.

FERNÁNDEZ, R.; ELIAS, L. G.; BRAHAM, J. E.; BRESSANI, R. Trypsin inhibitors and hemagglutinins in benas (Phaseolus vulgaris) and their relationship with the content of tannins and associated polyphenols. Journal of Agricultural and Food Chemistry, London, v. 30, n. 4, p. 734-739, July/Aug. 1982.

FERREIRA, D. F. Análises estatísticas por meio do Sisvar para windons versão 4.0. In: REUNIÃO ANUAL DA REGIÃO BRASILEIRA DA SOCIEDADE INTERNACIONAL DE BIOMETRIA, 45., 2000, São Carlos, SP. Anais... São Carlos: UFSCar, 2000. p. 255-258.

FIGUEROA, M.; LAJOLO, F. M. Effect of chemical modification of Phaseoulus vulgares lectins on their biological properties. Journal of Agricultural and Food Chemistry, London, v. 45, p. 639-643, 1997.

GENOVESE, M. I.; LAJOLO, F. M. Inativação dos inibidores de proteases de leguminosas: uma revisão. Boletim SBCTA, São Paulo, v. 34, n. 2, p. 107-112, 2000.

GOLDSTEIN, J. L.; SWAIN, T. Changes in tannins in ripening fruits. Phytochemistry, Oxford, v. 2, p. 371383, 1963.
HAFEZ, Y. S. Nutrient composition of different varieties and strains of soybean. Nutrition Reports International, Woburn, v. 28, n. 3, p. 1197-1206, 1983.

KAKADE, M. L.; RACKIS, J. J.; McGHEE, J. E.; PUSKI, G. Determination of trypsin inhibitor activity of soy product: a collaborative analysis of an improved procedure. Cereal Chemistry, Saint Paul, v. 51, p. 376382, 1974.

KAKADE, M. L.; SIMONS, N.; LIENER, I. E. An evaluation of natural vs. synthetic substrates for measuring the antitryptic activy of soybean samples. Cereal Chemistry, Saint Paul, v. 46, p. 518-526, 1969.

LIENER, I. E. Toxic constituents of plant foodstuffs. 2. ed. New York: Academic, 1980. 502 p.

LIENER, I. E. Nutritional significance of lectins in the diet. In: LIENER, I. E.; SHARON, N.; GOLDSTEIN, I. J. (Eds.). The lectins: properties, functions, and applications in biology and medicine. New York: Academic, 1986. 560 p.

LOURES, A.; JOKL, L. Microtécnica para determinação de ácido oxálico em folhas e derivados. In: ENCONTRO NACIONAL DE ANALISTAS DE ALIMENTOS, 6., 1990, Curitiba. Resumos... Curitiba: Instituto de Tecnologia do Paraná, 1990. p. 59.

MASSEY, L. K.; ROMAN-SMITH, H.; SUTTON, R. A. L. Effect of dietary oxalate and calcium on urinary oxalate and risk of formation of calcium oxalate kidney stones. Journal of the American Dietetic Association, Chicago, v. 93, n. 8, p. 901-906, Aug. 1993.

MONTEIRO, C. A. O mapa da pobreza no Brasil. Cadernos de Nutrição, São Paulo, v. 4, p. 1-6, 1992.

OSUNTOKUN, B. O. Cassava diet, chronic cyanide intoxification and neuropathy in Nigerien Africans. World Review Nutrition Dietetics, Basel, v. 36, p. 141-173, 1981.

PIMENTEL-GOMES, F. Curso de estatística experimental. 13. ed. São Paulo: Nobel, 1990. 467 p.

SALUNKHE, D. K.; JADHAV, S. J.; KADDAM, S. S.; CHAVAN, J. K. Chemical, biochemical and biological significance of polyphenol in cereals and legumes. CRC Critical Reviews in Food Science and Nutrition, Cleveland, v. 17, p. 277-279, 1982. 
SGARBIERI, V. C. Alimentação e nutrição: fator de saúde e desenvolvimento. São Paulo: Almed, 1987. 387 p.

SIMÕES, C. M. O.; SCHENKEL, E. P.; GOSMANN, G.; MELLO, J. C. P.; MENTZ, L. A.; PETROVICK, P. R. (Eds.). Farmacognosia: da planta ao medicamento. Porto Alegre: UFRGS; Florianópolis: UFSC, 2000.

SWAN, P. F. The toxicology of nitrate, nitrite and $\mathrm{N}$-nitroso compounds. Journal of the Science of Food and Agriculture, London, v. 26, n. 11, p. 1761-1770, Nov. 1975.
VIDAL-VALVERDE, C.; FRIAS, J.; ESTRELLA, I.; GOROSPE, M. J.; RUIZ, R.; BACON, J. Effect of processing on some antinutritional factors of lentils. Journal Agricultural Food Chemical, [S.l.], v. 42, n. 10, p. 2291-2295, 1994.

WALKER, R. Naturally occurring nitrate nitrate/nitrate in foods. Journal of the Science of Food and Agriculture, London, v. 26, n. 11, p. 1735-1742, Nov. 1975.

WOGAN, G. N.; MARLETTA, M. A. Componentes perjudiciales o potencialmente perjudiciales de los alimentos. In: FENNEMA, O. R. Química de los alimentos. 2. ed. Zaragoza: Acribia, 1993. p. 775-811. 